\title{
Herpes Zoster Duplex Bilateralis - A Case Report
}

\author{
Dr. S. Pavithra ${ }^{1}$, Dr. V. Sudha ${ }^{2}$, Dr. K. Divya Malar ${ }^{3}$, Dr. Pragna B Dolia ${ }^{4}$ \\ ${ }^{1}$ Senior Resident, Dept of Dermatology, ACS Medical College and Hospital, Chennai, India \\ ${ }^{2}$ Professor and HOD, Dept of Dermatology, ACS Medical College and Hospital, Chennai, India \\ ${ }^{3}$ Junior Resident, Dept of Dermatology, ACS Medical College and Hospital, Chennai, India \\ ${ }^{4}$ Professor and HOD, Dept of Biochemistry, ACS Medical College and Hospital, Chennai, India
}

\begin{abstract}
The phenomenon of herpes zoster occurring concurrently in two non-contiguous dermatomes involving different halves of the body is termed herpes zoster duplex bilateralis. Case reports of HZDB is very rare so we are reporting a case of HZDB in a newly detected diabetic male patient.
\end{abstract}

Keywords: herpes zoster, herpes zoster duplex bilateralis

\section{Introduction}

Herpes zoster (HZ) is a neuroectodermal viral infection which afflicts one or more closely grouped, spinal or cranial nerves, resulting in a unilateral radicular pain and vesicular eruption limited to a dermatome innervated by that nerve. It may result in post herpetic neuralgia, scarring and keloid formation.[1]

The phenomenon of herpes zoster occurring concurrently in two non-contiguous dermatomes involving different halves of the body is termed herpes zoster duplex bilateralis (HZDB).[2]

\section{Case Report}

A 45 year old male presented to the outpatient department with fluid filled lesions over the right side of face, nose. He complained of fever, pain, burning sensation and malaise. The lesions started 3 days back and increased in number, 2 days later he developed few similar lesions on left arm.

He was not a known diabetic / hypertensive/heart disease patient

He was a non smoker/non alcoholic

No h/o trauma/stress/ immunosuppressive therapy

O/E: multiple grouped vesicles overright side of face in the distribution of maxillary branch of trigeminal nerve. Erythema and edema present. Hutchinson sign positive. Few vesicles over left arm in the distribution of T1 dermatome.

Systemic examination : unremarkable

\section{On investigation:}

Tzank smear - multinucleated giant cells seen

Complete blood count, RFT, LFT - within normal limits

HIV, Hbsag- non reactive

Bloodsugar levels- raised

The patient was treated with oral acyclovir $800 \mathrm{mg}$ five times a day for a week along with analgesics and antipyretics. Physician opinion was taken and started on oral hypoglycaemic agents.
On follow up the patient had postherpetic neuralgia and was treated with T.amitryptilline.

\section{This case is reported here because}

- Cases of bilateral herpes zoster reported in literature is exceedingly rare accounting forless than $1 \%$ cases.[3]

- Though hutchinson's sign was positive, patient did not have ophthalmic complications.

\section{Discussion}

Varicella zoster virus (VZV) is a neurotropic human herpes virus. It causes both, chicken pox and herpes zoster (shingles). After causing chicken pox, it remains latent for decades in cranial nerves, dorsal root and autonomic nervous system ganglia. An effective immune system maintains the viral genome in latently infected cell and prevents viral replication and spread via retrograde axonal flow to the skin. Reactivation of $\mathrm{HZ}$ is usually confined to a single episode and a single dermatome, though the latent viral genomes are present in many peripheral sensory ganglia [2]

Factors reported to determine the occurrence of zoster include waning specific cell mediated immunity to VZV related to age, immunosuppressive disease or drug therapy, local trauma such as surgery, local therapeutic X-ray irradiation and possibly local musculoskeletal problem. Isolated case reports in the literature also document bilateral zoster. Undoubtedly such cases occur but they remain exceedingly rare accounting for less than $1.0 \%$ cases [3]

Multidermatomal and disseminated herpes zoster frequently occurs in patients with lymphoreticular malignancy or HIV infection, but is rare in immunocompetent persons [4]

Diabetes mellitus (DM) comprises a group of metabolic disorders that share the phenotype of hyperglycemia Individuals with DM have a greater frequency and severity of infections. Several rare infections are seen almost exclusively in diabetic population. The reasons for this include abnormality in cell mediated immunity and phagocyte functions associated with hyperglycemia[5] 


\section{International Journal of Science and Research (IJSR) \\ ISSN (Online): 2319-7064}

Index Copernicus Value (2016): 79.57 | Impact Factor (2015): 6.391

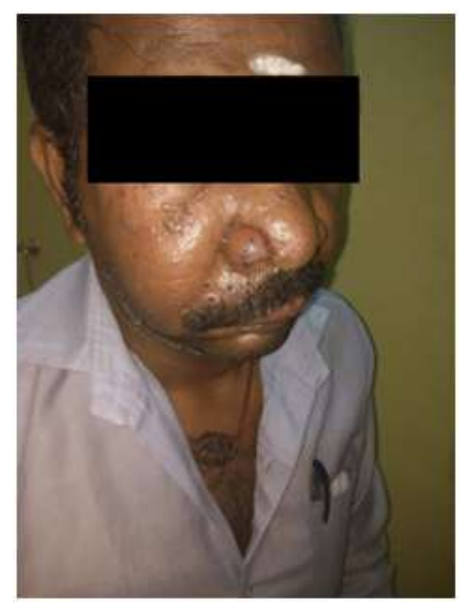

Figure 1: Shows vesicles in the distribution of maxillary branch of trigeminal nerve, right side

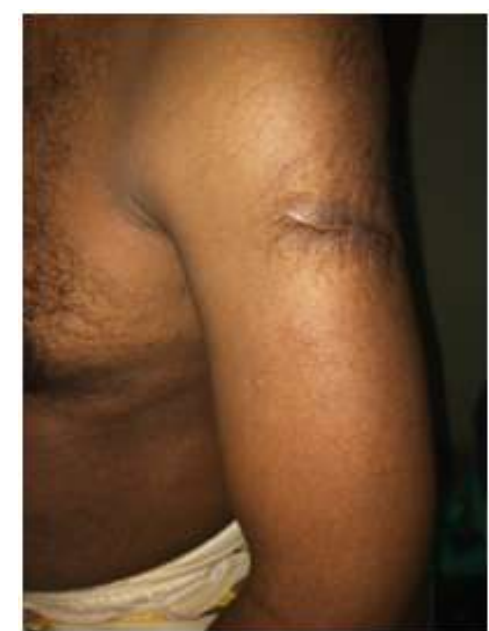

Figure 2: Shows vesicles in left arm

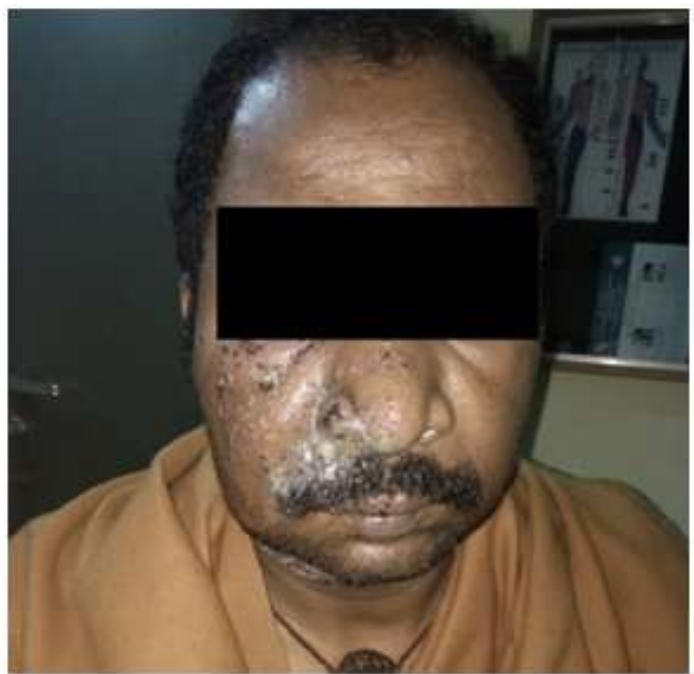

Figure 3: Crusts seen during treatment

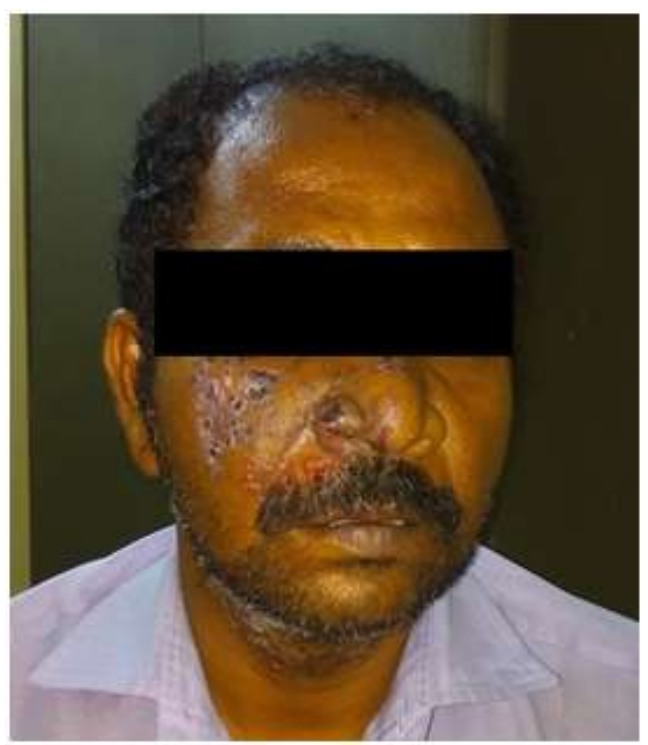

Figure 4: Shows resolution of edema, crusts seen on day 7 of treatment.

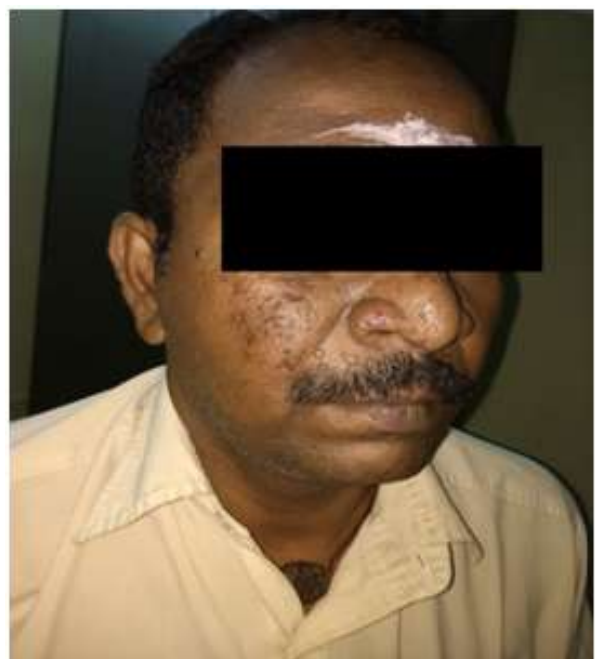

Figure 5: Shows atrophic scars during follow up after 3 months

\section{References}

[1] Brar B K, Gupta R R, Saghni S S. Bilateral herpes Zoster of widely separated dermatomes in a non Immunocompromised female. Indian $\mathrm{J}$ Dermatol Venereol Leprol 2002;68:48-9

[2] Gahalaut P, Chauhan S. Herpes zoster duplex bilateralis in an immunocompetent host. Indian Dermatology Online Journal. 2012;3(1):31-33 . doi:10.4103/22295178.93495 .

[3] Singh K G, Bajaj A K, Dwivedi N C, Merchery A. Bilateral herpes zoster. Indian J Dermatol Venereol Leprol 1993;59:90-2

[4] Gupta LK, Kuldeep C M, Mittal A, Singhal H. Multidermatomal herpes zoster in an immunocompetent female. Indian J Dermatol Venereol Leprol 2005;71:2101

[5] Nassaji-Zavareh M, Taheri R, Ghorbani R, Aminian M. Undiagnosed diabetes mellitus in patients with herpes zoster. Indian J Dermatol 2008;53:119-21

Volume 6 Issue 12, December 2017

www.ijsr.net 